\title{
Preface: Hydrological processes and water security in a changing world
}

\author{
Zhongbo Yu ${ }^{1}$, Chunhui Lu ${ }^{1}$, Jianyuan $\mathrm{Cai}^{2}$, Dazheng Yu${ }^{2}$, Gil Mahe ${ }^{3}$, Anil Mishra ${ }^{4}$, \\ Christophe Cudennec $^{5}$, Henny A. J. Van Lanen ${ }^{6}$, Didier Orange ${ }^{7}$, and Abou Amani ${ }^{4}$ \\ ${ }^{1}$ State Key Laboratory of Hydrology-Water Resources and Hydraulic Engineering, \\ Hohai University, Nanjing, China \\ ${ }^{2}$ Department of Hydrology, Ministry of Water Resources, Beijing, China \\ ${ }^{3} \mathrm{HSM}$, Hydrosciences, IRD, UM, CNRS, MSE, 34090 Montpellier, France \\ ${ }^{4}$ UNESCO, Division of Water Sciences, 7 place de Fontenoy, 75352 Paris CEDEX 07, France \\ ${ }^{5}$ UMR SAS, Institut Agro, INRAe, 35000 Rennes, France \\ ${ }^{6}$ Hydrology and Quantitative Water Management Group, Environmental Sciences Department, \\ Wageningen University, Droevendaalsesteeg 3a, 6708 PB Wageningen, the Netherlands \\ ${ }^{7}$ Eco\&Sols, UM, IRD, CIRAD, INRAe, SupAgro Montpellier, 34090 Montpellier, France
}

Correspondence: Zhongbo Yu (zyu@hhu.edu.cn, zhongbo.yu@gmail.com)

Published: 15 September 2020

The world's freshwater environment is changing rapidly and facing unprecedented pressures. A growing global population and economic development have led to increasing demands on water resources and water management. The impact of climate change and intensive anthropogenic activities is now posing a great threat on the hydrological cycle leading to various water issues, such as floods, droughts, over-exploitation of water resources, pollution, and ecosystem degradation in many countries. On a global scale, more than two billion people live in countries experiencing high water stress. Consequently, understanding hydrological responses to stresses at local, regional and global scales is critical for addressing these water issues, including water resources planning and management for everywhere on the planet.

In order to advance the knowledge of hydrological processes and flow regimes in different regions, UNESCO initiated in the 1980s the Flow Regimes from International Experimental and Network Data (FRIEND) programme (Van Lanen et al., 2014), within the framework of Intergovernmental Hydrological Program (IHP). The FRIEND programme is an international research programme that helps to set up regional networks for analyzing hydrological data. It aims to develop better understanding of hydrological variability and similarity across time and space, through the mutual exchange of data, knowledge and techniques at the re- gional level. FRIEND's track record shows its strengths as a global network supporting a science-based network of highlevel hydrological research at the river basin level and larger scales. These activities undertaken by FRIEND regional scientific groups of researchers, resulted in several topics related to regional hydrology and scientific publications, which is a contribution on water security within the framework of the IHP VIII and beyond to water related sustainable development goals (SDGs) of the United Nations Agenda 2030 for sustainable development, Paris Agreement and Sendai Framework.

The 8th Global FRIEND conference was co-organized by UNESCO and Government of China from 6-9 November 2018 in Beijing, with the focus on the theme of hydrological processes and water security in a changing world, under which eight thematic topics were discussed during the conference: (1) hydrological observations under the changing environment and scarcity; (2) river regimes and hydrological extremes under the changing environment; (3) simulation and prediction of surface water and groundwater processes under the impact of human activities; (4) urban hydrology and sponge city; (5) multi-objective water resources allocation and operation; (6) integrated watershed management including eco-hydrology and socio-hydrology; (7) water quality and sediment transport; and (8) river health and ecological baseflow under changing environment. The conference 
explored how society, water systems and the environment interact under changing conditions. It highlighted the advance in hydrological science and innovation in water management, as well as the solutions to improve this relationship, particularly in view of contributing to the 2030 Agenda and the Paris Agreement. For the first time the two IHP programs FRIEND and Ecohydrology jointly organized a side event about the importance to bring ecological solutions to hydrological problems.

The series of FRIEND conferences, workshops and scientific publications since 1989 are proven to be essential for fostering cooperation among FRIEND network and beyond. More than 200 participants from 44 countries attended the 8th Global FRIEND conference. This conference reminded that knowledge from all parts of the world need to be shared to improve our capacity to manage water as a common resource. More than 100 papers were presented at the conference. Eighty-nine papers were submitted for publication in this PIAHS volume, from which eventually 50 papers were accepted. These papers cover study areas in precipitation and climate impact; observation, analysis and simulations of hydrologic processes; floods in the changing environments; drought monitoring and analysis; water resources and environmental impacts.

Quantifying the natural and anthropogenic impacts on the hydrological processes and water resources are very important in current research efforts to understand how hydrological processes vary among climates and through time, as regional and global climates undergo change, and how modified hydrological processes affect water resources at different scales. Despite that many advances in these research areas have been achieved, the comprehensively integrated data and multidisciplinary approaches are required to address solutions for the implementation of SDGs and particularly water related targets. Furthermore, the outcome of the conference presented in the proceedings will be shared and discussed widely among IHP networks which would lead to recommend inputs for sustainable water resources management at different scale, but also provide feedbacks for the preparation of strategic plan for the ninth phase of IHP (IHP IX, 2022-2029).
The hydrological mechanisms, including flood and drought events, pollutions and water scarcity, underlie the climate-soil-vegetation dynamics and control the most basic ecological patterns and processes, both for biota and materials. Then the regional hydrology and flow regime characterization can emphasize the comprehension and role of the hydrological template that regulates ecohydrological functioning of the nature. Hydrological processes and water security are intrinsically linked to ecological and societal based approaches for watershed management. The future effort is at the nexus of water-soil-energy-food; and the related fields of geoinformatics, cyberinfrastructure in watersheds and remote measurements for scientific studies and water resources assessment should be helpful.

\section{References}

Van Lanen, H. A. J., Demuth, S., Daniell, T., Hannah, D.M., Laaha, G., Mahe, G., and Tallaksen, L. N.: Over 25 years of FRIEND-Water: an overview, in: Hydrology in a Changing World: Environmental and Human Dimensions, Proceedings of FRIEND-Water 2014, Montpellier, France, October 2014, edited by: Daniell, T. M., Van Lanen, H. A. J., Demuth, S., Laaha, G., Servat, E., Mahe, G., Boyer, J.-F., Paturel, J.-E., Dezetter, A., and Ruelland, D., Sci. Ed., IAHS Publ., 363, 1-7, 2014. 